\section{Discard Soviet doctorate systems}

The research performance of most former Soviet states is still low compared with that of many Western countries. In my view, progress will be stifled as long as the archaic academic systems passed down from the former Soviet Union persist.

I have analysed the research performance of several of these nations on the basis of their per capita gross expenditure on research and development (GERD; see go.nature. com/8oclnj) from 1998 to 2010 and their number of research publications from 1998 to 2012 (see www.scimagojr.com).

The Baltic countries - Estonia, Lithuania and Latvia - were notably more productive in 2012 than Russia, Ukraine and Belarus (see 'Research performance in former Soviet nations', left), with Estonia's publication output per 1,000 people approaching that of the United States (1.7 in 2012). Also, the research performance of the Baltic states has progressed markedly since 1998 (see figure, right).

The figure also shows that each country's publication output seems to have improved as research funding has increased. Georgia, however, had no increase in GERD between 1998 and 2005 (no more recent data are available), yet managed to more than triple its number of research publications between 1998 and 2012. Russia and Belarus have given a particularly poor return on investment in terms of research publications.

The success of Georgia and the Baltic states since 1998 may be connected with their adoption of internationally recognized standards for doctorate degrees and academic promotion. These countries now use a Western $\mathrm{PhD}$ model dedicated to original research, and career advancement depends on producing international peerreviewed publications - which is not the case in Russia, Ukraine,
Belarus and other former Soviet states.

Those poorly performing countries continue to use the old Soviet split-level doctorate degree. This degree can take more than 20 years to complete and involves only a minimal initial training in research, which may not be original and is not subject to independent peer review. The rest of a candidate's time is taken up with administrative tasks for example, preparing reports for committees and government departments.

The poor research performance in most former Soviet states stems partly from weak funding management (data not shown). But there is also an urgent need for fundamental academic reform in those countries.

Alexander Gorobets Sevastopol, Ukraine.

alex-gorobets@mail.ru

\section{Ranking Brazilian research output}

As presidents of the

Brazilian Association for the

Advancement of Science and the Brazilian Academy of Sciences, we object to your negative perspective on CAPES, our education ministry's agency for the Coordination for the Improvement of Higher Education Personnel (Nature 500, 510-511; 2013).

The impact factor is just one of a long list of indicators used by CAPES since 1976 to rate programmes in 48 fields of research, from social studies to physics. It is important to stress that the agency uses a system of peer review to evaluate and rank Brazil's graduate programmes not to assess individual curricula vitae. The country's scientific community analyses data on the performance of each programme over the previous three years.

Other indicators that CAPES evaluates include recognition of faculty members' research by the international community; the coherence, consistency

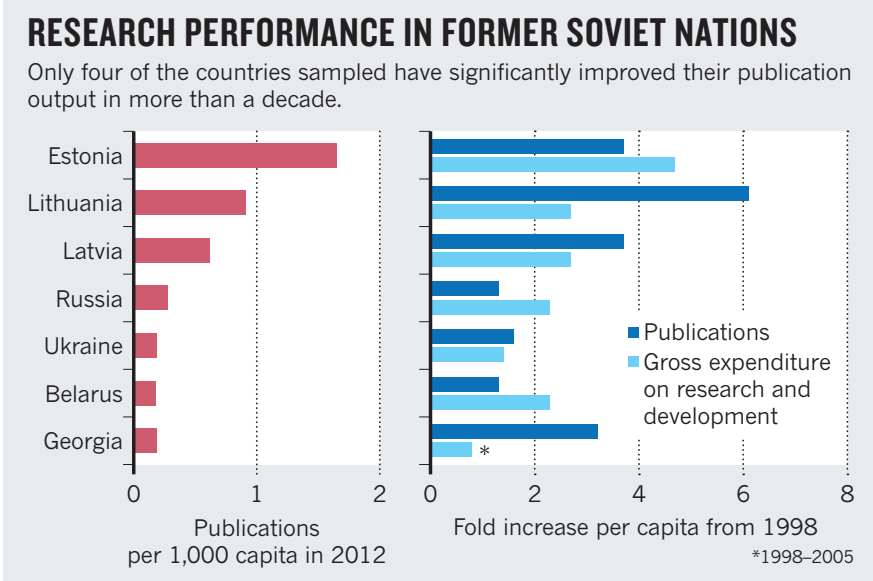

and comprehensiveness of the curriculum and infrastructure for teaching, research and continuing education; students' participation in research; and the contribution of faculty members to the supervision of doctoral students.

There are several ranking systems worldwide that also incorporate journal impact factors and citations into their metrics and are acknowledged by the scientific community. One is the Academic Ranking of World Universities (also known as the Shanghai Ranking), which inspired the Ranking Web (or Webometrics) for universities around the world.

Helena B. Nader Brazilian Association for the Advancement of Science, São Paulo, Brazil. hbnader.bioq@epm.br Jacob Palis Brazilian Academy of Sciences, Rio de Janeiro, Brazil.

\section{Russia embraced Wallace's works}

On the centenary of Alfred Russel Wallace's death this week, it is worth recalling the remarkable influence that the naturalist's ideas had in Russia during his lifetime. His major works were translated into Russian, including his books The Malay Archipelago (1869), Darwinism (1889) and Man's Place in the Universe (1903).

Although Wallace was most famous as Charles Darwin's co-discoverer of evolution by natural selection, the demand among Russian intellectuals was mainly for Wallace's own publications. Many warmed to Wallace's contention that human spiritual faculties cannot be explained by natural selection.

Theologians such as Alexander Gusev (1842-1904) used it to defend Orthodox Christianity against 'non-believers'. Gusev even accused the translators of Wallace's Contributions to the Theory of Natural Selection (1870) of censoring 'unscientific' ideas and of distorting Wallace's holistic view of science and religion (G. S. Levit and S. V. Polatayko Theor. Biosci. http://doi.org/pq8).

Russia's fascination with Wallace's work helped to evolutionists on alternative versions of Darwinism (see D. Todes Nature 462, 36-37; 2009) and opened up discussion on the uniqueness of the human soul.

Georgy S. Levit Friedrich Schiller University, Jena, Germany, University of King's College, Halifax, Nova Scotia, Canada, and National Research University ITMO, St Petersburg, Russia. Uwe Hossfeld Friedrich Schiller University, Jena, Germany, and National Research University ITMO, St Petersburg, Russia. Lennart Olsson Friedrich Schiller University, Jena, Germany.

lennart.olsson@uni-jena.de shape the debate among early 